\title{
Arthroscopic coronal plane syndesmotic instability has been over-diagnosed
}

\author{
Noortje C. Hagemeijer ${ }^{1,2,3,4}$ - Mohamed Abdelaziz Elghazy ${ }^{1,5} \cdot$ Gregory Waryasz $^{1,6} \cdot$ Daniel Guss $^{1,6,7}$. \\ Christopher W. DiGiovanni ${ }^{1,6,7}$. Gino M. M. J. Kerkhoffs ${ }^{2,3,4}$
}

Received: 22 October 2019 / Accepted: 14 May 2020 / Published online: 25 May 2020

(c) The Author(s) 2020

\begin{abstract}
Purpose Ankle arthroscopy is widely used for diagnosis of syndesmotic instability, especially in subtle cases. To date, no published article has systematically reviewed the literature in aggregate to understand which instability values should be used intraoperatively. The primary aim was to systematically review the amount of tibiofibular displacement that correlates with syndesmotic instability after a high ankle sprain. A secondary aim is to assess the quality of such research.

Methods Systematic searches of EMBASE (Ovid) and MEDLINE via PubMed, CINAHL, Web of Science, and Google Scholar were used. Inclusion criteria: studies that arthroscopically evaluated the fibular displacement at various stages of syndesmotic ligament injury. Two reviewers independently extracted data and assessed methodological quality using the Anatomical Quality Assessment (AQUA) Tool and methodological index for non-randomized studies (MINORS).

Results Eight cadaveric studies and three clinical studies were included for review. All studies reported displacement in the coronal plane, four studies reported in the sagittal plane, and one reported findings in the rotational plane. Four cadaveric studies had a similar experimental set up and the weighted mean associated with instability in the coronal plane could be calculated and was $2.9 \mathrm{~mm}$ at the anterior portion of the distal tibiofibular joint and $3.4 \mathrm{~mm}$ at the posterior portion. Syndesmotic instability in the sagittal plane is less extensively studied, however available data from a cadaveric study suggests thresholds of $2.2 \mathrm{~mm}$ of posterior fibular translation when performing an anterior to posterior hook test and $2.6 \mathrm{~mm}$ of anterior fibular translation when performing a posterior to anterior hook test.

Conclusions The results have concluded that the commonly used $2.0 \mathrm{~mm}$ threshold value of distal tibiofibular diastasis may lead to overtreatment of syndesmotic instability, and that using threshold values of $2.9 \mathrm{~mm}$ measured at the anterior portion of the incisura and $3.4 \mathrm{~mm}$ at the posterior portion may represent better cut off values. Given the ready availability of $3 \mathrm{~mm}$ probes among standard arthroscopic instrumentation, at the very least surgeons should use $3 \mathrm{~mm}$ in lieu of $2 \mathrm{~mm}$ probes intraoperatively.
\end{abstract}

Level of evidence IV.

Keywords Ankle arthroscopy $\cdot$ Syndesmosis $\cdot$ Tibiofibular joint $\cdot$ Instability $\cdot$ Cut off

Noortje C. Hagemeijer

nchagemeijer@gmail.com

1 Foot and Ankle Research and Innovation Lab, Department of Orthopaedic Surgery, Massachusetts General Hospital, Harvard Medical School, Boston, USA

2 Department of Orthopaedic Surgery, Amsterdam University Medical Center, University of Amsterdam, Amsterdam Movement Sciences, Amsterdam Zuidoost, The Netherlands

3 Academic Center for Evidence Based Sports Medicine (ACES), Amsterdam, The Netherlands
4 Amsterdam Collaboration for Health and Safety in Sports (ACHSS), AMC/VUMC IOC Research Center, Amsterdam, The Netherlands

5 Mansoura Faculty of Medicine, Mansoura University Hospital, Mansoura, Egypt

6 Foot and Ankle Service, Department of Orthopaedic Surgery, Massachusetts General Hospital, Boston, USA

7 Massachusetts General Hospital, Newton-Wellesley Hospital, Harvard Medical School, Boston, USA 


\section{Abbreviations}

AITFL Anterior interior tibiofibular ligament

AQUA Anatomical quality assessment tool

ATFL Anterior tibiofibular ligament

CFL Calcaneofibular ligament

CINHAL Cumulative index to nursing and allied health literature

DL Deltoid ligament

IOL Interosseous ligament

LFTCL Lateral fibulo-talo-calcaneal ligament complex

PITFL Posterior interior tibiofibular ligament

PTFL Posterior talofibular ligament

\section{Introduction}

Isolated syndesmotic injuries occur in approximately $18 \%$ of all ankle sprains and $10-23 \%$ of all ankle fractures [4, $19,25,35,54]$ and correlate with significantly poorer functional outcomes when left untreated [14, 42, 44]. The ankle draws much of its stability from its mortise structure, and instability of the distal tibiofibular ligamentous complex by definition allows this mortise to widen around the talus. The potentially altered tibiotalar relationship, in turn, can increase joint contact pressures potentiating post-traumatic arthritis [31, 41, 53]. Appropriate diagnosis and surgical repair of syndesmotic instability is, therefore, crucial towards preserving ankle stability and maximizing long term functional outcomes [23, 29].

MRI reliably detects syndesmotic injury, but as a static, unstressed modality, it is unable to reliably distinguish between stable and unstable injuries [22]. In contrast, ankle arthroscopy allows direct visualization of the distal tibiofibular articulation, both statically and under an applied stress load $[38,48]$. While recent clinical and cadaveric studies have highlighted the role of ankle arthroscopy in diagnosing syndesmotic instability, the amount of fibular motion correlated with instability remains unclear as reported cut off values vary among. Most studies have highlighted a cut off value between 2 and $3 \mathrm{~mm}$, but no published article has systematically reviewed these studies in aggregate to understand which values to use intraoperatively $[7,10,30]$.

The primary aim of this study is to systematically review the published literature exploring the amount of fibular displacement found that correlates with syndesmotic instability after a high ankle sprain. A secondary aim is to assess the quality of such research. The clinical relevance of the present study is that it will provide an instability cut off value based upon a meticulous summary of all the available primary research for diagnosing syndesmotic instability arthroscopically which will be directly usable in the clinic and improve clinical outcome.

\section{Materials and methods}

\section{Search strategy}

Studies from the earliest recorded citations until June 18, 2019 were retrieved from the following electronic databases: EMBASE (Ovid) and MEDLINE via PubMed, CINAHL, Web of Science, and Google Scholar (Table 1). When searching through Google Scholar, only the first 250 results were exported because their search algorithm demonstrated that, despite thousands of results, the relevancy of these results quickly dropped. The search was conducted under the guidance of a clinical librarian.

\section{Eligibility criteria}

All the studies that arthroscopically evaluated fibular displacement in the three planes after different type of ligamentous injuries were considered for inclusion. All randomized controlled trials, controlled non-randomized trials, prospective and retrospective cohort studies and case series were included. Animal studies and review studies were excluded, though the references of related review articles were assessed for any additional eligible studies. No age restrictions were applied.

\section{Variables and target outcome}

The target variables included, (1) the threshold considered to represent an unstable syndesmosis, (2) fibular displacement in the coronal, sagittal, and rotational plane in $\mathrm{mm}$ or degrees, (3) associated injuries, (4) location of the measurement, and (5) type of stress test. Associated injuries were defined as injuries to the ligamentous structures of the syndesmosis the anterior inferior tibiofibular ligament (AITFL), the interosseous ligament (IOL), and the posterior inferior tibiofibular ligament (PITFL), the lateral fibulo-talo-calcaneal ligament complex LFTCL, consisting of the anterior tibiofibular ligament (ATFL), calcaneofibular ligament (CFL), posterior talofibular ligament (PTFL) [51], the deltoid ligament (DL), and concomitant ankle fractures. Other reported diagnostic tools (radiographs, CT, MRI, or ultrasound) and intra- and inter-rater reliability scores were also recorded.

\section{Reference standard}

In cadaveric studies the ligamentous injury pattern was used as a reference when comparing the amount of fibular displacement across studies. Syndesmotic instability was defined as an injury that was associated with tibiofibular 
Table 1 Search strategy and hits per electronic database

\begin{tabular}{|c|c|c|c|c|}
\hline Database & Line & & Items found & Unique hits \\
\hline Pubmed & $\# 1$ & $\begin{array}{l}\text { (Arthroscop*[tiab] OR Arthroscopy[mesh]) AND (Syndesmos*[Title/Abstract] OR } \\
\text { syndesmotic[Title/Abstract] OR tibiofibular*[Title/Abstract] OR “tibio fibular”[Title/ } \\
\text { Abstract] OR “high ankle”[Title/Abstract] OR AITFL[Title/Abstract] OR PITFL[Title/ } \\
\text { Abstract]) AND (“Wounds and injuries”[Mesh:noexp] OR “Sprains and strains”[Mesh] } \\
\text { OR Rupture[Mesh:noexp] OR “Joint instability”[Mesh] OR “ankle injuries”[Mesh:noexp] } \\
\text { OR Injur*[Title/Abstract] OR sprain*[Title/Abstract] OR instabilit*[Title/Abstract] OR } \\
\text { unstable[Title/Abstract] OR rupture*[Title/Abstract] OR disruption*[Title/Abstract] OR } \\
\text { tear*[Title/Abstract] OR torn[Title/Abstract]) }\end{array}$ & 126 & 125 \\
\hline \multirow[t]{10}{*}{ Embase } & $\# 1$ & 'arthroscopy'/de OR 'ankle arthroscopy'/de & 159 & 54 \\
\hline & $\# 2$ & arthroscop*:ab,ti & & \\
\hline & \#3 & $\# 1 \mathrm{OR} \# 2$ & & \\
\hline & $\# 4$ & $\begin{array}{l}\text { ‘injury'/de OR ‘rupture'/de OR ‘ligament rupture'/de OR ‘joint instability'/de OR ‘sprain'/ } \\
\text { exp OR 'ligament injury'/de OR ‘ankle injury’/de OR ‘syndesmotic injury'/de }\end{array}$ & & \\
\hline & $\# 5$ & $\begin{array}{l}\text { injur*:ab,ti OR sprain*:ab,ti OR instabilit*:ab,ti OR unstable:ab,ti OR rupture*:ab,ti OR } \\
\text { disruption*:ab,ti OR tear*:ab,ti OR torn:ab,ti }\end{array}$ & & \\
\hline & \#6 & \#4 OR \#5 & & \\
\hline & $\# 7$ & 'syndesmosis'/exp & & \\
\hline & $\# 8$ & $\begin{array}{l}\text { syndesmos*:ab,ti OR syndesmotic:ab,ti OR tibiofibular*:ab,ti OR 'tibio fibular':ab,ti OR } \\
\text { 'high ankle':ab,ti OR aitfl:ab,ti OR pitfl:ab,ti }\end{array}$ & & \\
\hline & $\# 9$ & \#7 OR \#8 & & \\
\hline & $\# 10$ & \#3 AND \#6 AND \#9 & & \\
\hline \multirow[t]{8}{*}{ CINHAL } & S1 & (MH “Arthroscopy”) & 74 & 5 \\
\hline & S2 & TI Arthroscop* OR AB Arthroscop* & & \\
\hline & S3 & S1 OR S2 & & \\
\hline & S4 & $\begin{array}{l}\text { TI (Syndesmos* OR syndesmotic OR tibiofibular* OR “tibio fibular" OR "high ankle” OR } \\
\text { AITFL OR PITFL) OR AB (Syndesmos* OR syndesmotic OR tibiofibular* OR “tibio } \\
\text { fibular" OR "high ankle" OR AITFL OR PITFL) }\end{array}$ & & \\
\hline & S5 & $\begin{array}{l}\text { (MH "Ankle Injuries") OR (MH “Ankle Sprain+") OR (MH "Sprains and Strains") OR (MH } \\
\text { "Wounds and Injuries") OR (MH "Rupture") OR (MH "Joint Instability") }\end{array}$ & & \\
\hline & S6 & $\begin{array}{l}\text { TI (Injur* OR sprain* OR instabilit* OR unstable OR rupture* OR disruption* OR tear* OR } \\
\text { torn) OR AB (Injur* OR sprain* OR instabilit* OR unstable OR rupture* OR disruption* } \\
\text { OR tear* OR torn) }\end{array}$ & & \\
\hline & S7 & S5 OR S6 & & \\
\hline & S8 & S3 AND S4 AND S7 & & \\
\hline \multirow[t]{4}{*}{ Web of science } & $\# 1$ & TOPIC: (Arthroscop*) & 144 & 52 \\
\hline & $\# 2$ & $\begin{array}{l}\text { TOPIC: (Syndesmos* OR syndesmotic OR tibiofibular* OR "tibio fibular" OR "high ankle" } \\
\text { OR AITFL OR PITFL) }\end{array}$ & & \\
\hline & $\# 3$ & $\begin{array}{l}\text { TOPIC: (Injur* OR sprain* OR instabilit* OR unstable OR rupture* OR disruption* OR } \\
\text { tear* OR torn) }\end{array}$ & & \\
\hline & $\# 4$ & $\begin{array}{l}\text { \#1 AND \#2 AND \#3 Indexes=SCI-EXPANDED, SSCI, A\&HCI, CPCI-S, CPCI-SSH, } \\
\text { BKCI-S, BKCI-SSH, ESCI, CCR-EXPANDED, IC Timespan=All years }\end{array}$ & & \\
\hline Google scholar & $\# 1$ & $\begin{array}{l}\text { Arthroscopy | arthroscope I Syndesmoses I syndesmosis I syndesmotic | tibiofibular | "tibio } \\
\text { fibular" | "high ankle" | AITFL I PITFL Injury I injuries I sprain I sprains | instability | } \\
\text { unstable | rupture I disruption I tear I torn }\end{array}$ & 500 & 252 \\
\hline Total & & & 1003 & 488 \\
\hline
\end{tabular}

displacement significantly different from the intact state. In In vivo studies, this comparison cannot be made and, therefore, the threshold considered to represent an unstable syndesmosis and associated injuries was described descriptively for each study.

\section{Study selection}

Two authors (NH and MA) independently screened titles and abstracts, using predetermined inclusion and exclusion criteria with the help of Covidence, https://www.covidence. 
org/home. Disagreement was resolved by an attempt to reach consensus. In cases where no consensus was reached, a third reviewer $(\mathrm{GW})$ was consulted to resolve the disagreement.

\section{Data extraction}

Data were extracted by one reviewer $(\mathrm{NH})$ and thereafter checked by all co-authors. Extracted data were collected in a predefined format from Microsoft Excel for Mac (version 15.37). Study design, patient or cadaver characteristics, arthroscopic measurement details, diastasis measurements or pre-determined cut off values, related injuries, and other radiographic outcomes were extracted.

\section{Quality assessment}

Methodological quality of the cadaveric studies was assessed using the Anatomical Quality Assessment (AQUA) Tool by two independent reviewers (NC and MA) [18]. This tool is designed to help evaluate the performed experiment, i.e. the arthroscopic diagnosis of syndesmotic instability, by addressing five key domains: (1) whether objectives were clearly defined and appropriate, (2) whether the study design was appropriate for answering the aims, (3) whether the methodology was described in sufficient detail to permit replication, (4) whether the anatomical definitions were accurately defined and described, and (5) whether the results were accurately calculated and reported. The methodological quality of included studies was assessed using the Methodological Index for Non-Randomized Studies (MINORS) instrument [46]. MINORS is an instrument designed to assess methodological quality of both non-comparative and comparative studies. For this study, only the non-comparative factors of the MINORS instrument were used. Disagreement was resolved by consensus or third-party adjudication (GW).

\section{Statistical analysis}

For each study, the reported amount of distal tibiofibular displacement, associated injury patterns, and related pathologies were recorded and summarized. Statistical heterogeneity was then determined using the Higgins and Thompson $I^{2}$ index as well as a chi-squared test to assess for heterogeneity. The $I^{2}$ was considered to be of low heterogeneity when $<0.25$, moderate heterogeneity when between 0.25 and 0.50 , and high heterogeneity when $>0.50$. A fixed model was used when heterogeneity was low or moderate. If the data heterogeneity was high, a formal meta-analysis would not be performed and instead results would be presented in a descriptive manner along with weighted means and SDs when able. In case of unavailable raw data the range of the means would be provided instead. $P$-values of $<0.05$ were considered significant. All analyses were performed with Stata 13.0 for Mac (StataCorp LP, College Station, TX, USA).

\section{Results}

A total of 1003 studies were identified (Fig. 1). Of these studies, 515 were duplicates and removed prior to the first round of selection. Of those remaining, 389 articles were excluded based upon title and abstract screen and 98 articles were selected for full-text screening. A total of 8 cadaveric studies and three clinical studies were included in this systematic review [12, 15, 16, 26, 27, 30, 31, 50, 53, 56]. Three studies' corresponding authors were contacted by email for additional information but were not ultimately included due to non-response [40, 49, 52].

\section{Variables and target outcome}

The threshold that was considered to represent an unstable syndesmosis, amount of displacement, associated injury patterns, and arthroscopy technique details per each study are summarized in Table 2.

All cadaveric studies reported on fibular displacement in the coronal plane. Significant tibiofibular displacement from the intact state ranged from 1.6 to $4.4 \mathrm{~mm}$ at the anterior and from 2.4 to $4.4 \mathrm{~mm}$ at the posterior third of the incisura [15, $27,31,32,53]$. One study provided an instability threshold based upon a cluster analysis, which was $2.6 \mathrm{~mm}$ when measuring at the anterior third coronal plane space of the incisura, and $3.4 \mathrm{~mm}$ when measuring at the posterior third space [26]. The other two cadaveric studies did not compare tibiofibular displacement to the reference intact state [12, 27]. Due to a high heterogeneity, a formal meta-analysis was not performed and weighted means for syndesmotic instability in the coronal plane were calculated instead for those cadaveric studies who had a similar experimental set up including probe positioning, method of stress application, and the absence of use of an ankle distractor [15, 27, $31,32]$. The weighted mean of syndesmotic instability in the coronal plane with a lateral fibular stress maneuver was $2.9 \mathrm{~mm}$ at the anterior portion of the incisura and $3.4 \mathrm{~mm}$ at the posterior portion of the incisura. Weighted means of syndesmotic instability and per each injury pattern are provided in Table 3.

All three in vivo studies reported on displacement in the coronal plane. Two of these chose to use the threshold of $>2 \mathrm{~mm}$ for diagnosing and treating syndesmotic instability $[30,56]$. The other study categorized each injury pattern based upon the diastasis in a self-made grading scheme where they considered $<2 \mathrm{~mm}$ stable, $>2$ to $<5 \mathrm{~mm}$ potentially unstable, and $>5 \mathrm{~mm}$ unstable [50]. 


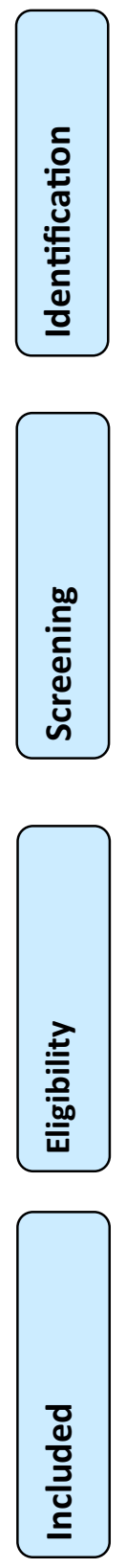
Records identified through database searching $(n=1,003)$

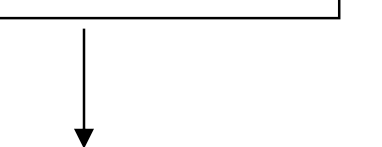

\section{Additional records identified through other sources}

$(n=0)$

Records after duplicates removed

$(n=488)$
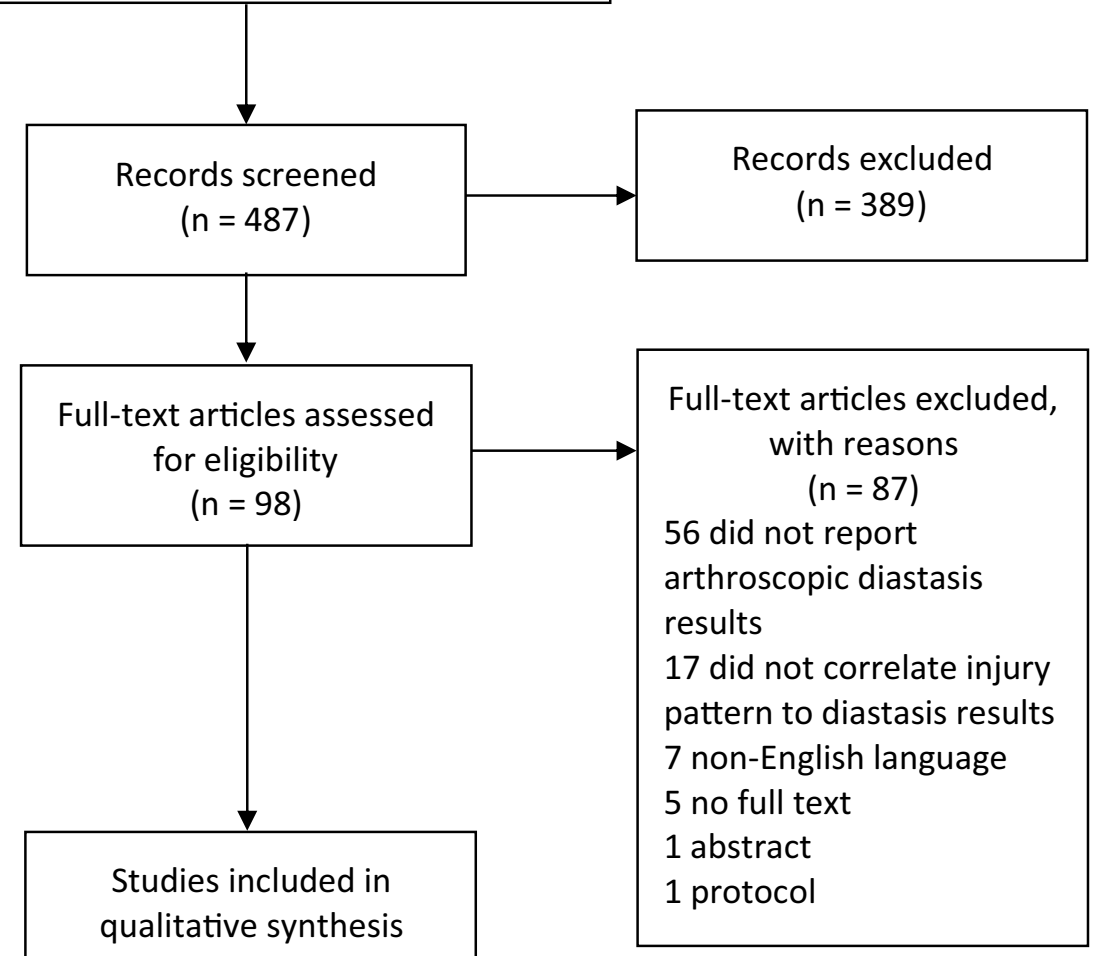

$$
(n=11)
$$

Fig. 1 PRISMA (preferred reporting items for systematic meta-analyses) flowchart for study inclusion. RCT randomized controlled trial

Three cadaveric studies reported on tibiofibular displacement values in the sagittal plane [26, 27, 53]. One study provided an instability threshold based upon a cluster analysis which was $2.2 \mathrm{~mm}$ when pulling anteriorly, and $2.6 \mathrm{~mm}$ when pulling posteriorly [26]. Two studies presented their results descriptively [27, 53].

Only one In vivo study reported on displacement in the sagittal plane, handling a threshold of $>2 \mathrm{~mm}$ for diagnosing and treating syndesmosis instability [30].

None of the cadaveric studies reported findings in the rotational plane. One clinical study reported findings in the rotational plane for which they handled a threshold of $>2 \mathrm{~mm}$ [30].

Feller et al. and Lui et al. reported concomitant radiographic measurements for each injury pattern, which are presented in Table $4[15,30]$.

Two clinical studies reported on in vivo cartilage damage in the setting of syndesmotic instability [50,56]. Turky et al. [50] reported that over $90 \%$ of the patients had additional lesions also including ATFL injuries. All four patients described by Yoshimura et al. [56] had talar lesions on the posteromedial aspect of the talar dome. 
There were two cadaveric studies which included an inter-observer agreement analysis as part of their study methodology, which both derived from the same experimental set up, by having two observers assess three specimens independently $[26,27]$. Substantial agreement was found for anterior third coronal plane tibiofibular diastasis and sagittal plane tibiofibular translation. Moderate agreement was found for posterior third coronal plane tibiofibular diastasis.

\section{Quality assessment}

All but two studies had a high risk of bias due to a methodology that was not described in sufficient detail to permit

Table 2 Arthroscopic syndesmotic instability measurements per study

\begin{tabular}{|c|c|c|c|c|c|}
\hline Author & Characteristics & Arthroscopic measurement details & Coronal stress (mm) & Sagittal stress (mm) & $\begin{array}{l}\text { Rotational stress } \\
(\mathrm{mm})\end{array}$ \\
\hline $\begin{array}{l}\text { Lui et al. } 2005 \\
\text { Country: China } \\
\text { Design: } \\
\text { prospective } \\
\text { study } \\
\text { Period: } 06 / 2002 \\
12 / 2003\end{array}$ & $\begin{array}{l}\text { nr: } 53 \\
\text { Age: } 35.4 \\
\text { Sex: NR } \\
\text { Cohort: } \\
\text { Surgically } \\
\text { treated Weber } \\
\text { type B or C } \\
\text { ankle fractures } \\
\text { without } \\
\text { radiographic } \\
\text { evidence of } \\
\text { frank } \\
\text { syndesmosis } \\
\text { diastasis }\end{array}$ & 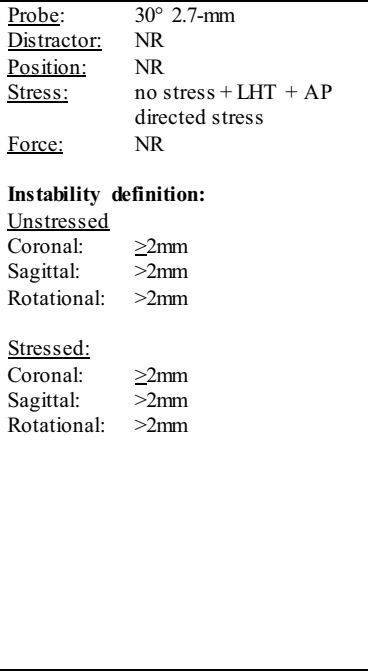 & $\begin{array}{l}\text { Stable injury }(<\mathbf{2 m m}) \\
\text { Stressed } \\
\text { Total: } 32 \\
11 \text { intact } \\
2 \text { AITFL } \\
2 \text { AITFL+pIOL } \\
10 \text { AITFL+IOL } \\
1 \text { AITFL+IOL+pPITFL } \\
2 \text { AITFL+IOL+PITFL } \\
4 \text { AITFL+IOL+\#PITFL } \\
\text { Unstable injury }(>2 \mathbf{m m}) \\
\text { Unstressed } \\
\text { Total: } 10 \\
7 \text { AITFL+IOL+PITFL } \\
3 \text { AITFL+IOL+\#PITFL } \\
\text { Stressed } \\
\text { Total: 11 } \\
1 \text { IOL+PITFL } \\
9 \text { AITFL+IOL+PITFL } \\
1 \text { AITFL+IOL+\#PITFL } \\
1 \text { AITFL+IOL+pPITFL }\end{array}$ & $\begin{array}{l}\text { Stable injury }(<2 \mathbf{m m}) \\
\text { Stressed } \\
\text { Total: } 30 \\
11 \text { intact } \\
1 \text { AITFL } \\
2 \text { AITFL+pIOL } \\
7 \text { AITFL+IOL } \\
2 \text { AITFL+IOL+pPITFL } \\
3 \text { AITFL+IOL+PITFL } \\
4 \text { AITFL+IOL+\#PITFL } \\
\text { Unstable injury }(>2 \mathbf{m m}) \\
\text { Unstressed } \\
\text { Total: } 16 \\
2 \text { AITFL-IOL } \\
12 \text { AITFL-IOL-PITFL } \\
2 \text { AITFL+IOL+\#PITFL } \\
\text { Stressed } \\
\text { Total: } 7 \\
1 \text { IOL+PITFL } \\
3 \text { AITFL+IOL+PITFL } \\
3 \text { AITFL+IOL+\#PITFL }\end{array}$ & $\begin{array}{l}\text { Stable injury }(<\mathbf{2 m m}) \\
\text { Stressed } \\
\text { Total } 39 \\
11 \text { intact } \\
2 \text { AITFL } \\
2 \text { AITFL+pIOL } \\
7 \text { AITFL+IOL } \\
15 \\
\text { AITFL+IOL+PITFL } \\
2 \\
\text { AITFL+IOL+\#PITFL } \\
\text { Stable injury }(>\mathbf{2 m m}) \\
\text { Unstressed: } \\
\text { Total 12 } \\
4 \text { AITFL-IOL } \\
1 \text { AITFL-IOL- } \\
\text { partialPITFL } \\
2 \text { AITFL-IOL-PITFL } \\
5 \text { AITFL-IOL+PITFL\# } \\
\text { Stressed: } \\
\text { Total: } 2 \\
1 \text { AITFL-IOL- } \\
\text { partialPITFL } \\
1 \text { AITFL-IOL+PITFL\# }\end{array}$ \\
\hline 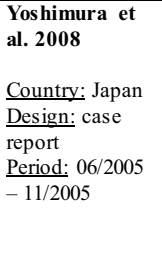 & $\begin{array}{l}\text { Nr: } 4 \\
\text { Age: } 24.5 \\
\text { Sex: } 4 \text { males } \\
\text { Cohort: } \\
\text { Surgically } \\
\text { treated } \\
\text { Maisonneuve } \\
\text { fractures }\end{array}$ & $\begin{array}{ll}\text { Probe: } & 30^{\circ} 2.7 \mathrm{~mm} \\
\text { Distractor: } & \text { yes } \\
\text { Position: } & \text { NR } \\
\text { Stress: } & \text { ER } \\
\text { Force: } & \text { NR } \\
& \\
\text { Instability } & \text { definition: } \\
\text { Coronal: } & >2 \mathrm{~mm} \\
\text { Sagittal: } & \mathrm{NR} \\
\text { Rotational: } & \mathrm{NR}\end{array}$ & $\begin{array}{l}\text { Stable injury }<\mathbf{2} \mathbf{~ m m} \\
\text { none } \\
\text { Unstable injury }>\mathbf{2} \mathbf{m m} \\
3 \text { AITFL-IOL } \\
\text { 1 AITFL-IOL-DL (or medial } \\
\text { malleolar fracture) }\end{array}$ & NR & NR \\
\hline $\begin{array}{l}\text { Watson et al. } \\
2015 \\
\text { Country: USA } \\
\text { Design: } \\
\text { Cadaveric study } \\
\text { Period: NR }\end{array}$ & $\begin{array}{l}\text { Nr: } 7(\mathrm{C}) \\
\text { Age: NR } \\
\text { Sex: NR } \\
\text { Cohort: } \\
\text { unmatched } \\
\text { below knee } \\
\text { cadavers }\end{array}$ & 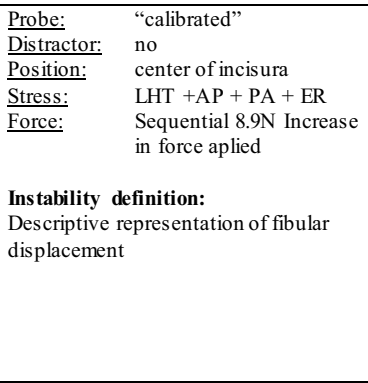 & \begin{tabular}{ll}
\multicolumn{2}{l}{ Intact-[AITFL+IOL]- } \\
[ATFL+CFL]-PITFL \\
Olbs: & $98 \mathrm{~N}:$ \\
0 & $\mathrm{NR}$ \\
0.4 & 0 \\
2.6 & 3.8 \\
grossly unstable & grossly unstable
\end{tabular} & $\begin{array}{ll}\text { Intact-[AITFL+IOL]- } \\
\text { [ATFL+CFL]-PITFL } \\
\text { PA stress } \\
0 \text { lbs: } & 22 \mathrm{lbs}: \\
0.2 & \mathrm{NR} \\
0.9 & 1.0 \\
5.2 & 6.4 \\
\text { grossly unstable } & \text { grossly unstable } \\
& \\
\text { AP stress } & \\
0 \text { lbs: } & 22 \mathrm{lbs}: \\
0.20 & \mathrm{NR} \\
1.0 & 1.4 \\
0.3 & 0.8 \\
\text { grossly unstable } & \text { grossly unstable }\end{array}$ & 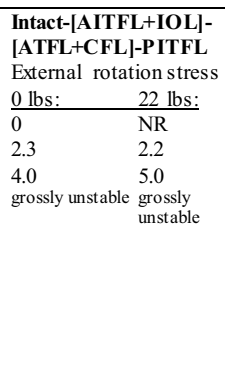 \\
\hline $\begin{array}{l}\text { Feller et al. } \\
2016 \\
\text { Country: USA } \\
\text { Design: } \\
\text { Cadaveric study } \\
\text { Period: NR }\end{array}$ & $\begin{array}{l}\text { Nr: } 10(\mathrm{C}) \\
\text { Age: } 58.3 \\
\underline{\text { Sex: }} 8 \text { males } \\
\text { Cohort: } \\
\begin{array}{l}\text { unmatched } \\
\text { above knee }\end{array}\end{array}$ & 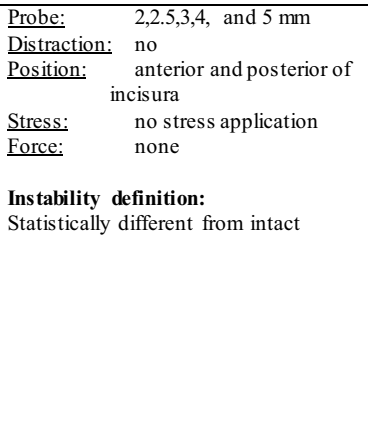 & 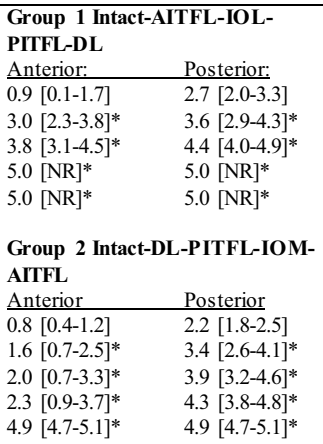 & $\mathrm{NR}$ & NR \\
\hline
\end{tabular}


Table 2 (continued)

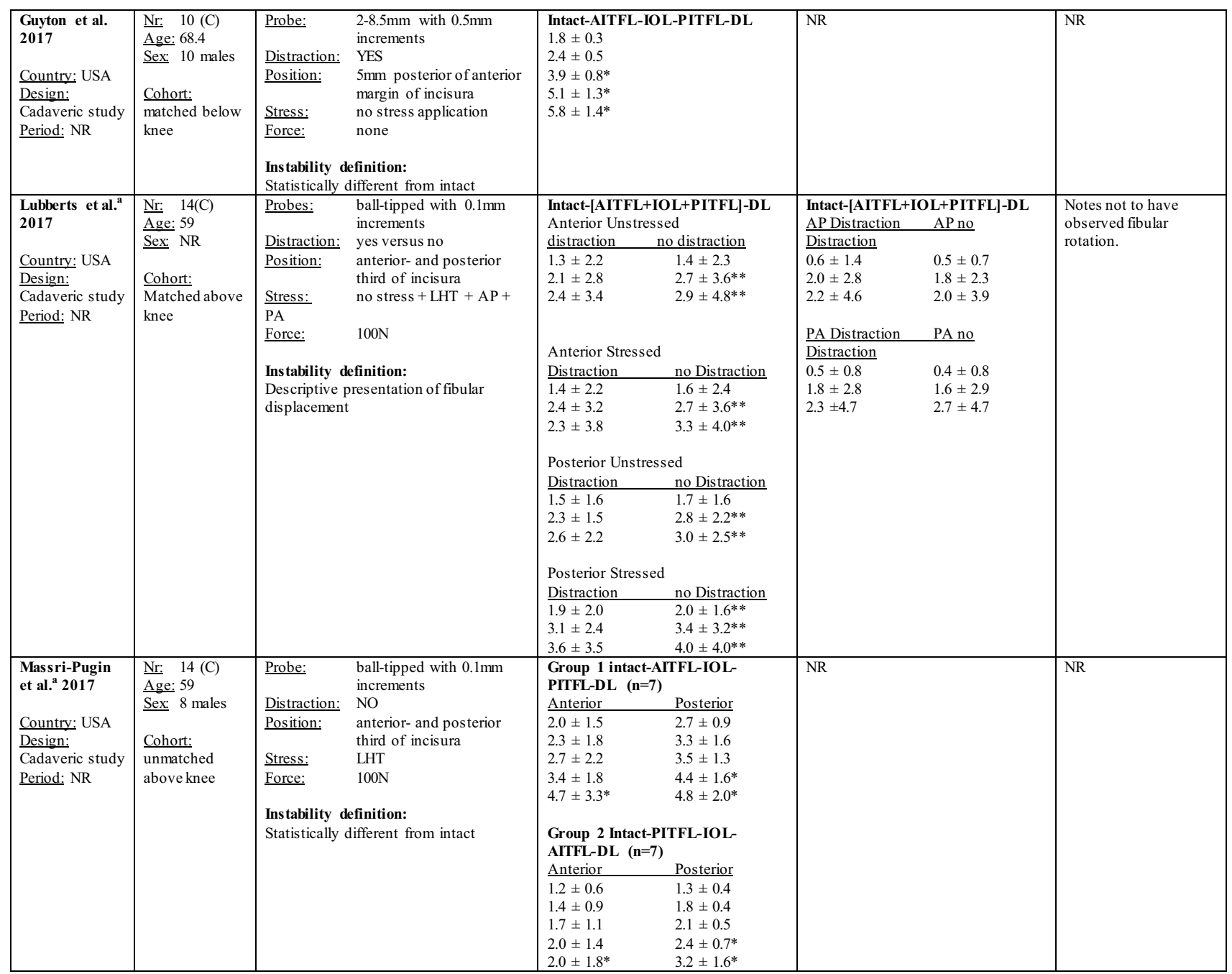


Table 2 (continued)

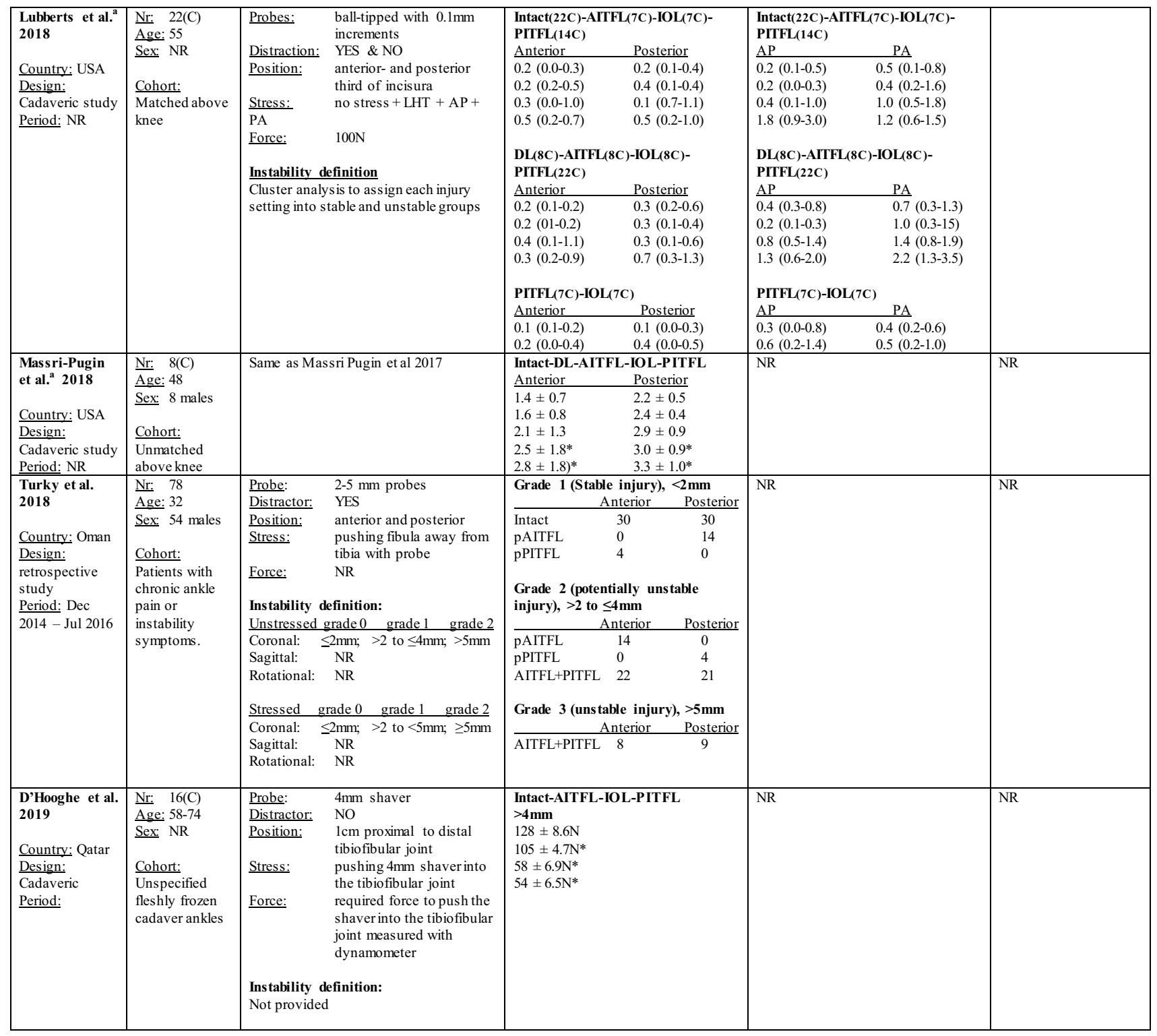

Syndesmotic instability measurements obtained with the arthroscope expressed in mean \pm SD, mean [95\% CI], or median(IQR) in millimeters per ligament transection stage, stress condition, probe position, and with- or without traction application. Values listed which derived from cadaveric studies correlate with the injury order as stated from top to bottom

$m m$ millimeters, $n r$ number, $N R$ not reported, $L H T$ lateral hook test, $A P$ anterior to posterior, $P A$ posterior to anterior, $A I T F L$ anterior inferior tibiofibular ligament, $I O L$ interosseous ligament, PITFL posterior inferior tibiofibular ligament, $D L$ deltoid ligament, $A T F L$ anterior talofibular ligament, $C F L$ calcaneal talofibular ligament, $p$ partial, \# fracture, USA United States of America, $C$ Cadaver, $N$ Newton, $l b s$ pounds

*Significant difference from intact

**Significant difference as compared to distraction

${ }^{\text {a }}$ Studies derived from the same experimental set up

replication as per the AQUA tool described above (Table 5). This specifically pertained to a failure to undertake appropriate measures to reduce inter- and intra- observer variability. The only studies included in this review that explicitly analyzed the reliability of the measurements were the studies of
Lubberts et al. [26, 27]. The methodological quality of the clinical studies was graded according to the MINORS criteria (Table 6 ) and the average score was 6.7 out 16 points (41.7\% of maximum). 
Table 3 Weighted means of the arthroscopic diastasis measurements in the coronal plane

\begin{tabular}{lll}
\hline Number of transected ligaments & $\begin{array}{l}\text { Anterior incisura (range of means) } \\
(\mathrm{mm})\end{array}$ & $\begin{array}{l}\text { Posterior incisura } \\
\text { (range of means) } \\
(\mathrm{mm})\end{array}$ \\
\hline Intact & $1.4(0.8-2)$ & $2.1(1.3-3.3)$ \\
One ligament & $2.0(1.4-3)$ & $2.6(1.6-3.6)$ \\
Two ligaments & $2.4(1.7-3.8)$ & $3.3(2.1-4.4)$ \\
Three ligaments & $3.0(2-5)$ & $3.7(2.4-5)$ \\
Syndesmotic instability value* & $2.9(1.6-4.7)$ & $3.4(2.4-4.4)$ \\
\hline
\end{tabular}

*The syndesmotic instability weighted mean value was calculated using the tibiofibular displacement values from those injury patterns that showed a significant difference from the intact state

Table 4 Fluoroscopic syndesmotic instability measurements per study

\begin{tabular}{|c|c|c|c|c|}
\hline \multirow[t]{2}{*}{ Author } & \multirow[t]{2}{*}{ Cohort and methods } & \multicolumn{3}{|l|}{ Measurements } \\
\hline & & TFO (mm) & TFCS (mm) & MCS (mm) \\
\hline $\begin{array}{l}\text { Lui et al. (2005) } \\
\text { Country: China } \\
\text { Design: prospective study } \\
\text { Period: } 06 / 2002-12 / 2003\end{array}$ & $\begin{array}{l}\text { Nr: } 53 \\
\text { Age: } 35.4 \\
\text { Sex: NR } \\
\text { Cohort: surgically treated } \\
\text { Weber type B or C ankle } \\
\text { fractures without radiographic } \\
\text { evidence of frank syndesmosis } \\
\text { diastasis }\end{array}$ & NR & $\begin{array}{l}\text { Injury patterns which did not show widening: } \\
11 \text { Intact } \\
2 \text { AITFL } \\
2 \text { AITFL + IOL }{ }_{\text {partial }} \\
9 \text { AITFL + IOL } \\
1 \text { IOL + PITFL } \\
2 \text { AITFL + IOL + }{ }_{\text {pITFL }} \\
4 \text { AITFL + IOL + PITFL } \\
5 \text { AITFL + IOL + PITFL\# } \\
\text { Injury patterns which did show widening: } \\
14 \text { AITFL + IOL + PITFL } \\
3 \text { AITFL + IOL + PITFL\# }\end{array}$ & NR \\
\hline Feller et al. (2016) & Nr: $10(C)$ & Group 1 Intact- & Group 1 Intact-AITFL-IOL-PITFL-DL & Group 1 Intact- \\
\hline Country: USA & Age: 58.3 & AITFL-IOL- & $4.7(3.5-5.9)$ & AITFL-IOL- \\
\hline Design: Cadaveric study & Sex: 8 males & PITFL-DL & $5.4(4.5-6.3)^{*}$ & PITFL-DL \\
\hline \multirow[t]{12}{*}{ Period: NR } & Cohort: & $4.9(4.3-5.6)$ & $5.6(4.8-6.4)$ & $4.0(3.1-4.9)$ \\
\hline & \multirow[t]{11}{*}{ unmatched above knee } & $4.4(3.63-5.7)$ & $7.53(5.9-9.2)$ & $4.0(3.3-4.6)$ \\
\hline & & $2.8(2.4-3.2)^{*}$ & $11.46(10.1-12.8)^{*}$ & $5.0(3.9-6.2)$ \\
\hline & & $1.5(0.1-2.9)^{*}$ & & $5.7(4.5-7.0)^{*}$ \\
\hline & & $<0(\mathrm{NR})$ & & $\begin{array}{l}9.8(8.11- \\
11.5)^{*}\end{array}$ \\
\hline & & $\begin{array}{l}\text { Group } 2 \text { Intact- } \\
\text { DL-PITFL- }\end{array}$ & $\begin{array}{l}\text { Group } 2 \text { Intact-AITFL-IOL-PITFL-DL } \\
5.5(5.0-6.0)\end{array}$ & $\begin{array}{l}\text { Group } 2 \text { Intact- } \\
\text { AITFL-IOL- }\end{array}$ \\
\hline & & IOM-AITFL & $5.4(4.3-6.5)^{*}$ & PITFL-DL \\
\hline & & $4.7(3.5-5.9)$ & $5.3(4.3-6.4)$ & $4.8(3.9-5.7)$ \\
\hline & & $3.8(3.0-4.6)$ & $6.1(4.8-7.3)$ & $4.9(4.2-5.7)$ \\
\hline & & $3.0(2.0-4.0)^{*}$ & $11.1(9.3-12.9)^{*}$ & $5.64(5.0-6.3)$ \\
\hline & & $2.2(1.6-2.7)^{*}$ & & $5.8,(4.7-6.8)^{*}$ \\
\hline & & $<0(\mathrm{NR})$ & & $10.3,(4.7-6.8)^{*}$ \\
\hline
\end{tabular}

TFO tibiofibular overlap, TFCS tibiofibular clear space, $M C S$ medial clear space, $m m$ millimeters, $n r$ number, $N R$ not reported, $A I T F L$ anterior inferior tibiofibular ligament, $I O L$ interosseous ligament, PITFL posterior inferior tibiofibular ligament, $D L$ deltoid ligament, $p$ partial, \# fracture, $C$ Cadaver

*Significant difference from intact

\section{Discussion}

The most important finding of this study is that the commonly used threshold of $2.0 \mathrm{~mm}$ potentially leads to overtreatment and using $3.0 \mathrm{~mm}$ of tibiofibular diastasis measured at the anterior portion of the incisura or $3.4 \mathrm{~mm}$ of tibiofibular diastasis at the posterior portion seems to be a better cut off value.

Syndesmotic instability can cause significant long-term morbidity if undiagnosed and even subtle persistent syndesmotic instability can already be very disabling. The latter can be difficult to appreciate with clinical maneuvers 
Table 5 Summary table for the risk of bias across the included studies

\begin{tabular}{|c|c|c|c|c|c|}
\hline \multirow[t]{2}{*}{ STUDY } & \multicolumn{5}{|l|}{ RISK OF BIAS } \\
\hline & $\begin{array}{l}\text { OBJECTIVE(S) AND } \\
\text { STUDY } \\
\text { CHARACTERISTICS }\end{array}$ & $\begin{array}{l}\text { STUDY } \\
\text { DESIGN }\end{array}$ & $\begin{array}{l}\text { METHODOLOGY } \\
\text { CHARACTERIZATION }\end{array}$ & $\begin{array}{l}\text { DESCRIPTIVE } \\
\text { ANATOMY }\end{array}$ & $\begin{array}{l}\text { REPORTING } \\
\text { OF } \\
\text { RESULTS }\end{array}$ \\
\hline $\begin{array}{l}\text { Lui et al. } \\
2005\end{array}$ & High & Low & High & Low & High \\
\hline $\begin{array}{l}\text { Yoshimura } \\
\text { et al. } 2008\end{array}$ & High & Low & High & Low & High \\
\hline $\begin{array}{l}\text { Watson et al. } \\
2015\end{array}$ & High & High & High & Low & High \\
\hline $\begin{array}{l}\text { Feller et al. } \\
2016\end{array}$ & Low & Low & High & Low & Low \\
\hline $\begin{array}{l}\text { Guyton et al. } \\
2017\end{array}$ & Low & Low & High & Low & High \\
\hline $\begin{array}{l}\text { Lubberts et } \\
\text { al. } 2017\end{array}$ & Low & Low & Low & Low & Low \\
\hline $\begin{array}{l}\text { Massri- } \\
\text { Pugin et al. } \\
2017\end{array}$ & Low & Low & High & Low & Low \\
\hline $\begin{array}{l}\text { Lubberts et } \\
\text { al. } 2018\end{array}$ & Low & Low & Low & Low & Low \\
\hline $\begin{array}{l}\text { Massri- } \\
\text { Pugin et al. } \\
2018\end{array}$ & Low & Low & High & Low & Low \\
\hline Turky et al. & Low & Low & High & Low & High \\
\hline $\begin{array}{l}\text { D'Hooghe et } \\
\text { al. }\end{array}$ & High & High & High & Low & High \\
\hline
\end{tabular}

High risk: red, low risk: green, unclear risk: blue 
Table 6 Quality assessment of the included clinical studies using the MINORS criteria

\begin{tabular}{llllllllllllll}
\hline Authors & Year & Journal & Evidence & Study design & 1 & 2 & 3 & 4 & 5 & 6 & 7 & 8 & Total \\
\hline Lui et al. & 2005 & Arthroscopy & II & Cohort study & 0 & 2 & 1 & 1 & 0 & 0 & 0 & 0 & 6 \\
Yoshimura et al. & 2008 & Orthopaedic science & IV & Case series & 2 & 1 & 0 & 2 & 0 & 1 & 0 & 0 & 7 \\
Turky et al. & 2018 & Foot and ankle surgery & III & Cohort study & 2 & 2 & 2 & 1 & 0 & 0 & 0 & 0 & 7 \\
\hline
\end{tabular}

Only the non-comparative part of the MINORS criteria was used (i.e. first 8 questions). The criteria of Methodological Index for Non-Randomized Studies (MINORS) with 0 points when not reported, 1 when reported but not adequate, and 2 when reported and adequate. Maximum score is 16

1. A clearly stated aim: the question addressed should be precise and relevant in the light of available literature

2. Inclusion of consecutive patients: all patients potentially fit for inclusion (satisfying the criteria for inclusion) have been included in the study during the study period (no exclusion or details about the reasons for exclusion)

3. Prospective collection of data: data were collected according to a protocol established before the beginning of the study

4. End points appropriate to the aim of the study: unambiguous explanation of the criteria used to evaluate the main outcome which should be in accordance with the question addressed by the study. In addition, the end points should be assessed on an intention-to-treat basis

5. Unbiased assessment of the study end point: blind evaluation of objective end points and double-blind evaluation of subjective end points. Otherwise, the reasons for not blinding should be stated

6. Follow-up period appropriate to the aim of the study: the follow-up should be sufficiently long to allow the assessment of the main endpoint and possible adverse events

7. Loss to follow-up less than 5\%: all patients should be included in the follow-up. Otherwise, the proportion lost to follow-up should not exceed the proportion experiencing the major end point

8. Prospective calculation of the study size: information of the size of detectable difference of interest with a calculation of $95 \% \mathrm{CI}$, according to the expected incidence of the outcome event, and information about the level for statistical significance or with static imaging. This has generated increasing interest in directly visualizing the distal tibiofibular articulation arthroscopically. Despite the fact that ankle arthroscopy has been proposed as the gold standard for diagnosing (subtle) syndesmotic instability, no prior literature review has systematically evaluated the available published research detailing arthroscopic examination of syndesmotic instability [16]. In total, 11 studies were ultimately included in this review, though high heterogeneity did not allow a formal meta-analysis.

Syndesmotic instability is inherently multidimensional and is comprised of tibiofibular diastasis in the coronal plane, fibular translation in the sagittal plane, and fibular external rotation $[5,20]$. The majority of the published literature, however, evaluates the syndesmosis primarily in the coronal plane while applying a lateral fibular "hook test". Several cut off values have been proposed by various authors, including $1 \mathrm{~mm}$ with stress application [11], $>2 \mathrm{~mm}$ without stress application [17], $>2 \mathrm{~mm}$ with stress application $[7,8,21,28,49],>3 \mathrm{~mm}$ without stress application [52], > $3 \mathrm{~mm}$ with stress application $[1,11,38],>4 \mathrm{~mm}$ without stress application [8], and $>4 \mathrm{~mm}$ with stress application [43]. Most studies used $2 \mathrm{~mm}$ as a cut off value, but this may over-diagnose syndesmotic instability and $3 \mathrm{~mm}$ may instead serve as a better cut off value in the coronal plane $[3,15,16,26,31,32,53]$. In this review, the weighted mean of syndesmotic instability in the coronal plane with a lateral fibular stress maneuver was $2.9 \mathrm{~mm}$ at the anterior portion of the incisura and $3.4 \mathrm{~mm}$ at the posterior portion of the incisura.

Syndesmotic instability in the sagittal plane is less welldescribed in the arthroscopic literature. Those that did investigate sagittal plane instability found that the instability is more visible in the sagittal plane than in the coronal plane in the setting of an unstable syndesmosis [6, 26, 27, 30, 38, 45, $53,55]$. However, the total amount of sagittal plane fibular translation that best serves as a clinical threshold for diagnosing syndesmotic instability remains uncertain. Lubberts et al. created a prediction model based on cluster analysis of data from a cadaveric syndesmotic injury model, which incorporated coronal as well as the sagittal plane measurements for assessing syndesmotic instability [26]. They reported cut off values of $2.2 \mathrm{~mm}$ of posterior fibular translation when performing an anterior to posterior hook test and $2.6 \mathrm{~mm}$ of anterior fibular translation when performing a posterior to anterior hook test [26].

Rotational plane stability is rarely assessed arthroscopically in the published literature. One clinical study included in this systematic review evaluated the rotation by assessing the difference between the distance from the anterior border to the incisura and the distance between the posterior border and the incisura [30]. Given that this value can be 
confounded by concomitant coronal and sagittal plane translation, the arthroscope may not be the preferred method for determining fibular rotation [30].

Technical factors also influence the amount of tibiofibular diastasis visualized arthroscopically, including (1) the amount of stress applied and in which direction [12, 26, 39,47 ], (2) whether a distractor is being used [27], and (3) where in the incisura the diastasis is being measured [15, $26,31,32]$. Stoffel et al. highlighted that stress forces above $100 \mathrm{~N}$ do not result in additional diastasis, and, therefore, numerous studies have standardized a $100 \mathrm{~N}$ force applied to the fibula $5 \mathrm{~cm}$ proximal to the tibiotalar joint in either the coronal or sagittal planes [26, 27, 31, 32, 47]. Furthermore, an ankle distractor is almost universally employed during arthroscopic procedures to the ankle, but this traction can mask syndesmotic instability, likely due to the applied tension to the surrounding intact ligaments and other soft tissues. Distraction should, therefore, be released at the time of measurement, especially if the syndesmotic instability is anticipated to be subtle [15, 27, 37]. Last, measurements in the posterior third of the incisura may result in higher values than those anteriorly $[15,31,32]$.

It is important to note that the reported distinction between a stable and unstable syndesmotic measurement value in the literature, as assessed arthroscopically, is a statistical one. The threshold values for instability, as discussed above, are those in which an injury to the syndesmosis has allowed the fibula to translate, either coronally or sagittally, on average significantly more than in the intact state. On the other hand, the degree of diastasis or translation that has clinical implications remains unclear and may or may not entirely correlate with the discussed values. Determination of the clinical effect of the various cut off values will be challenging given that it would require a randomized controlled or a multi-center observational study in which different surgeons use different thresholds.

Ankle arthroscopy does also have some inherent disadvantages. It is an invasive technique and, consequently, available to a select group of patients with either a high level of pre-operative suspicion or patients with a concomitant fracture that independently require surgery. Furthermore, unlike imaging modalities, arthroscopy cannot benefit from using the contralateral side as an internal control, which becomes increasingly useful as instability becomes more subtle, especially in chronic injury scenarios [13, 24, 36]. Diagnostic techniques that are non-invasive, dynamic, and allow for a bilateral examination at the same time will therefore almost undoubtedly play an increasing role in diagnosing syndesmotic instability in the future alongside the arthroscope. Modalities such as weightbearing CT or dynamic ultrasound fit the above criteria, and their roles should be further explored in both biomechanical and clinical studies $[2,5,33,34]$.
Two papers included in this review also assessed radiographic or fluoroscopic measurements $[15,30]$. They corroborated other radiographic studies highlighting that parameters such as tibiofibular overlap, tibiofibular clear space and medial clear space, do not seem sufficiently sensitive to diagnose syndesmotic instability $[9,22]$.

This review has some limitations. The overall quality of the included studies was low and there was a high risk of bias. For the experimental studies the low quality was most commonly due to a lack of intra- and inter-observer reliability measurements. Secondly, this study used the AQUA assessment tool, which is specifically designed for evaluating the methodology of an anatomic experiment and was therefore deemed most applicable for inclusion of cadaveric studies, but this tool is only now undergoing the process of being formally validated [18]. Last, ligamentous injury pattern was used as a reference standard when comparing the amount of fibular displacement across studies for the same injury and was used to calculate the weighted means. It should be noted that the injury pattern seen in a clinical setting does not invariably correlate with instability [30, 50, 56]. Clinical instability likely also relies on other potential patient factors (e.g. age, weight, and chronicity), but it may also result from a measurement bias given that the forces used in the various stress tests used are often not reported in the literature.

\section{Conclusion}

The results have concluded that the commonly used $2.0 \mathrm{~mm}$ threshold value of distal tibiofibular diastasis may lead to overtreatment of syndesmotic instability, and that using threshold values of $2.9 \mathrm{~mm}$ measured at the anterior portion of the incisura and $3.4 \mathrm{~mm}$ at the posterior portion may represent better cut off values. Given the ready availability of $3 \mathrm{~mm}$ probes among standard arthroscopic instrumentation, at the very least surgeons should use $3 \mathrm{~mm}$ in lieu of $2 \mathrm{~mm}$ probes intraoperatively.

Acknowledgements We thank Lisa Liang Philpotts, BSN, MSLS of the Massachusetts General Hospital Treadwell Library for her assistance with the literature search.

Author contributions Each author has made substantial contributions to the conception and design of the study, or acquisition of data, or analysis and interpretation of data, and drafting the article or revising it critically for important intellectual content. Each author read and approved the manuscript and believes that the manuscript represents honest work. Each author agrees to be accountable for all aspects of the work in ensuring that questions related to the accuracy or integrity of any part of the work are appropriately investigated and resolved. $\mathrm{NCH}$ participated in the design, the data acquisition, analysis, interpretation, manuscript drafting, and critical revision. MEA participated in 
the design, the data acquisition, analysis, interpretation, manuscript drafting, and critical revision. GW participated in the design, interpretation, and critical revision. DG participated in the design, interpretation, manuscript drafting, and critical revision. CWD participated in the design, interpretation, manuscript drafting, and critical revision. GMMJK participated in the design, interpretation, manuscript drafting, and critical revision.

Funding No authors reported receiving funding for this study.

\section{Compliance with ethical standards}

Conflict of interest Dr. DiGiovanni reports non-financial support from FAI, FAO, Eur J FAS outside the submitted work. Dr. Guss reports other support from Extremity Medical, outside the submitted work.

Ethical approval This article does not contain any studies with human participants or animals performed by any of the authors

Open Access This article is licensed under a Creative Commons Attribution 4.0 International License, which permits use, sharing, adaptation, distribution and reproduction in any medium or format, as long as you give appropriate credit to the original author(s) and the source, provide a link to the Creative Commons licence, and indicate if changes were made. The images or other third party material in this article are included in the article's Creative Commons licence, unless indicated otherwise in a credit line to the material. If material is not included in the article's Creative Commons licence and your intended use is not permitted by statutory regulation or exceeds the permitted use, you will need to obtain permission directly from the copyright holder. To view a copy of this licence, visit http://creativecommons.org/licenses/by/4.0/.

\section{References}

1. Ahn TK, Choi SM, Kim JY, Lee WC (2017) Isolated syndesmosis diastasis: computed tomography scan assessment with arthroscopic correlation. Arthroscopy 33(4):828-834

2. Anand Prakash A (2018) Syndesmotic stability: Is there a radiological normal? A systematic review. Foot Ankle Surg 24(3):174-184

3. Beumer A, Valstar ER, Garling EH, Niesing R, Ginai AZ, Ranstam J et al (2006) Effects of ligament sectioning on the kinematics of the distal tibiofibular syndesmosis: a radiostereometric study of 10 cadaveric specimens based on presumed trauma mechanisms with suggestions for treatment. Acta Orthop 77(3):531-540

4. Boytim MJ, Fischer DA, Neumann L (1991) Syndesmotic ankle sprains. Am J Sports Med 19(3):294-298

5. Burssens A, Vermue H, Barg A, Krahenbuhl N, Victor J, Buedts K (2018) Templating of syndesmotic ankle lesions by use of 3D analysis in weightbearing and nonweightbearing CT. Foot Ankle Int 39(12): 1487-1496

6. Candal-Couto JJ, Burrow D, Bromage S, Briggs PJ (2004) Instability of the tibio-fibular syndesmosis: have we been pulling in the wrong direction? Injury 35(8):814-818

7. Chan KB, Lui TH (2016) Role of ankle arthroscopy in management of acute ankle fracture. Arthroscopy 32(11):2373-2380

8. Choi WJ, Lee JW, Han SH, Kim BS, Lee SK (2008) Chronic lateral ankle instability: the effect of intra-articular lesions on clinical outcome. Am J Sports Med 36(11):2167-2172

9. Chun DI, Cho JH, Min TH, Park SY, Kim KH, Kim JH et al (2019) Diagnostic accuracy of radiologic methods for ankle syndesmosis injury: a systematic review and meta-analysis. J Clin Med 8(7):968

10. Chun KY, Choi YS, Lee SH, Kim JS, Young KW, Jeong MS et al (2015) Deltoid ligament and tibiofibular syndesmosis injury in chronic lateral ankle instability: magnetic resonance imaging evaluation at $3 \mathrm{~T}$ and comparison with arthroscopy. Korean J Radiol 16(5):1096-1103

11. Colcuc C, Fischer S, Colcuc S, Busse D, Bliemel C, Neun O et al (2016) Treatment strategies for partial chronic instability of the distal syndesmosis: an arthroscopic grading scale and operative staging concept. Arch Orthop Trauma Surg 136(2):157-163

12. D'Hooghe P, Chambers MC, Hogan MV, Musahl V, Alkhelaifi $\mathrm{K}$, Montassar T et al (2019) Determining the force required in arthroscopic evaluation to assess the stability of syndesmotic ankle injury: a cadaveric study. JISAKOS 4(2):100

13. Dikos GD, Heisler J, Choplin RH, Weber TG (2012) Normal tibiofibular relationships at the syndesmosis on axial CT imaging. J Orthop Trauma 26(7):433-438

14. Egol KA, Pahk B, Walsh M, Tejwani NC, Davidovitch RI, Koval KJ (2010) Outcome after unstable ankle fracture: effect of syndesmotic stabilization. J Orthop Trauma 24(1):7-11

15. Feller R, Borenstein T, Fantry AJ, Kellum RB, Machan JT, Nickisch F et al (2017) Arthroscopic quantification of syndesmotic instability in a cadaveric model. Arthroscopy 33(2):436-444

16. Guyton GP, DeFontes K 3rd, Barr CR, Parks BG, Camire LM (2017) Arthroscopic correlates of subtle syndesmotic injury. Foot Ankle Int 38(5):502-506

17. Han SH, Lee JW, Kim S, Suh JS, Choi YR (2007) Chronic tibiofibular syndesmosis injury: the diagnostic efficiency of magnetic resonance imaging and comparative analysis of operative treatment. Foot Ankle Int 28(3):336-342

18. Henry BM, Tomaszewski KA, Ramakrishnan PK, Roy J, Vikse J, Loukas M et al (2017) Development of the anatomical quality assessment (AQUA) tool for the quality assessment of anatomical studies included in meta-analyses and systematic reviews. Clin Anat 30(1):6-13

19. Hopkinson WJ, St Pierre P, Ryan JB, Wheeler JH (1990) Syndesmosis sprains of the ankle. Foot Ankle 10(6):325-330

20. Huber T, Schmoelz W, Bolderl A (2012) Motion of the fibula relative to the tibia and its alterations with syndesmosis screws: a cadaver study. Foot Ankle Surg 18(3):203-209

21. Kim S, Huh YM, Song HT, Lee SA, Lee JW, Lee JE et al (2007) Chronic tibiofibular syndesmosis injury of ankle: evaluation with contrast-enhanced fat-suppressed 3D fast spoiled gradientrecalled acquisition in the steady state MR imaging. Radiology 242(1):225-235

22. Krahenbuhl N, Weinberg MW, Davidson NP, Mills MK, Hintermann B, Saltzman CL et al (2018) Imaging in syndesmotic injury: a systematic literature review. Skeletal Radiol 47(5):631-648

23. Krahenbuhl N, Weinberg MW, Hintermann B, Haller JM, Saltzman CL, Barg A (2019) Surgical outcome in chronic syndesmotic injury: a systematic literature review. Foot Ankle Surg 25(5):691-697

24. Lepojarvi S, Niinimaki J, Pakarinen H, Leskela HV (2016) Rotational dynamics of the normal distal tibiofibular joint with weightbearing computed tomography. Foot Ankle Int 37(6):627-635

25. Lubberts B, D'Hooghe P, Bengtsson H, DiGiovanni CW, Calder J, Ekstrand J (2019) Epidemiology and return to play following isolated syndesmotic injuries of the ankle: a prospective cohort study of 3677 male professional footballers in the UEFA Elite Club Injury Study. Br J Sports Med 53(15):959-964

26. Lubberts B, Guss D, Vopat BG, Johnson AH, van Dijk CN, Lee H et al (2020) The arthroscopic syndesmotic assessment tool can differentiate between stable and unstable ankle syndesmoses. Knee Surg Sports Traumatol Arthrosc 28(1):193-201 
27. Lubberts B, Guss D, Vopat BG, Wolf JC, Moon DK, DiGiovanni CW (2017) The effect of ankle distraction on arthroscopic evaluation of syndesmotic instability: a cadaveric study. Clin Biomech (Bristol, Avon) 50:16-20

28. Lubberts B, Massri-Pugin J, Guss D, Wolf JC, Bhimani R, Waryasz GR et al (2020) Arthroscopic assessment of syndesmotic instability in the sagittal plane in a cadaveric model. Foot Ankle Int 41(2):237-243

29. Lubberts B, van Dijk PAD, Donovan N, van Dijk CN, Calder JD (2016) Stable and unstable grade II syndesmotic injuries require different treatment strategies and vary in functional outcomes: a systematic review. JISAKOS 1(4):192

30. Lui TH, Ip K, Chow HT (2005) Comparison of radiologic and arthroscopic diagnoses of distal tibiofibular syndesmosis disruption in acute ankle fracture. Arthroscopy 21(11):1370

31. Massri-Pugin J, Lubberts B, Vopat BG, Guss D, Hosseini A, DiGiovanni CW (2017) Effect of sequential sectioning of ligaments on syndesmotic instability in the coronal plane evaluated arthroscopically. Foot Ankle Int 38(12):1387-1393

32. Massri-Pugin J, Lubberts B, Vopat BG, Wolf JC, DiGiovanni CW, Guss D (2018) Role of the deltoid ligament in syndesmotic instability. Foot Ankle Int 39(5):598-603

33. Mei-Dan O, Carmont M, Laver L, Nyska M, Kammar H, Mann G et al (2013) Standardization of the functional syndesmosis widening by dynamic US examination. BMC Sports Sci Med Rehabil 5:9

34. Mei-Dan O, Kots E, Barchilon V, Massarwe S, Nyska M, Mann $\mathrm{G}$ (2009) A dynamic ultrasound examination for the diagnosis of ankle syndesmotic injury in professional athletes: a preliminary study. Am J Sports Med 37(5):1009-1016

35. Mulcahey MK, Bernhardson AS, Murphy CP, Chang A, Zajac T, Sanchez G et al (2018) The epidemiology of ankle injuries identified at the National Football League Combine, 2009-2015. Orthop J Sports Med 6(7):2325967118786227

36. Nault ML, Hebert-Davies J, Laflamme GY, Leduc S (2013) CT scan assessment of the syndesmosis: a new reproducible method. J Orthop Trauma 27(11):638-641

37. Ogilvie-Harris DJ, Gilbart MK, Chorney K (1997) Chronic pain following ankle sprains in athletes: the role of arthroscopic surgery. Arthroscopy 13(5):564-574

38. Ogilvie-Harris DJ, Reed SC (1994) Disruption of the ankle syndesmosis: diagnosis and treatment by arthroscopic surgery. Arthroscopy 10(5):561-568

39. Ogilvie-Harris DJ, Reed SC, Hedman TP (1994) Disruption of the ankle syndesmosis: biomechanical study of the ligamentous restraints. Arthroscopy 10(5):558-560

40. Ono A, Nishikawa S, Nagao A, Irie T, Sasaki M, Kouno T (2004) Arthroscopically assisted treatment of ankle fractures: arthroscopic findings and surgical outcomes. Arthroscopy 20(6):627-631

41. Ramsey PL, Hamilton W (1976) Changes in tibiotalar area of contact caused by lateral talar shift. J Bone Jt Surg Am 58(3):356-357

42. Ray R, Koohnejad N, Clement ND, Keenan GF (2019) Ankle fractures with syndesmotic stabilisation are associated with a high rate of secondary osteoarthritis. Foot Ankle Surg 25(2):180-185
43. Ryan PM, Rodriguez RM (2016) Outcomes and return to activity after operative repair of chronic latent syndesmotic instability. Foot Ankle Int 37(2):192-197

44. Saltzman CL, Salamon ML, Blanchard GM, Huff T, Hayes A, Buckwalter JA et al (2005) Epidemiology of ankle arthritis: report of a consecutive series of 639 patients from a tertiary orthopaedic center. Iowa Orthop J 25:44-46

45. Sin YH, Lui TH (2019) Arthroscopically assisted reduction of sagittal-plane disruption of distal tibiofibular syndesmosis. Arthrosc Tech 8(5):e521-e525

46. Slim K, Nini E, Forestier D, Kwiatkowski F, Panis Y, Chipponi J (2003) Methodological index for non-randomized studies (minors): development and validation of a new instrument. ANZ J Surg 73(9):712-716

47. Stoffel K, Wysocki D, Baddour E, Nicholls R, Yates P (2009) Comparison of two intraoperative assessment methods for injuries to the ankle syndesmosis. A cadaveric study. J Bone Jt Surg Am 91(11):2646-2652

48. Takao M, Ochi M, Oae K, Naito K, Uchio Y (2003) Diagnosis of a tear of the tibiofibular syndesmosis. The role of arthroscopy of the ankle. J Bone Jt Surg Br 85(3):324-329

49. Takao M, Uchio Y, Naito K, Fukazawa I, Kakimaru T, Ochi M (2004) Diagnosis and treatment of combined intra-articular disorders in acute distal fibular fractures. J Trauma 57(6):1303-1307

50. Turky M, Menon KV, Saeed K (2018) Arthroscopic grading of injuries of the inferior tibiofibular syndesmosis. J Foot Ankle Surg 57(6):1125-1129

51. Vega J, Malagelada F, Manzanares Cespedes MC, Dalmau-Pastor M (2020) The lateral fibulotalocalcaneal ligament complex: an ankle stabilizing isometric structure. Knee Surg Sports Traumatol Arthrosc 28(1):8-17

52. Wagener ML, Beumer A, Swierstra BA (2011) Chronic instability of the anterior tibiofibular syndesmosis of the ankle. Arthroscopic findings and results of anatomical reconstruction. BMC Musculoskelet Disord 12:212

53. Watson BC, Lucas DE, Simpson GA, Berlet GC, Hyer CF (2015) Arthroscopic evaluation of syndesmotic instability in a cadaveric model. Foot Ankle Int 36(11):1362-1368

54. Wright RW, Barile RJ, Surprenant DA, Matava MJ (2004) Ankle syndesmosis sprains in national hockey league players. Am J Sports Med 32(8):1941-1945

55. Xenos JS, Hopkinson WJ, Mulligan ME, Olson EJ, Popovic NA (1995) The tibiofibular syndesmosis. Evaluation of the ligamentous structures, methods of fixation, and radiographic assessment. J Bone Jt Surg Am 77(6):847-856

56. Yoshimura I, Naito M, Kanazawa K, Takeyama A, Ida T (2008) Arthroscopic findings in Maisonneuve fractures. J Orthop Sci 13(1):3-6

Publisher's Note Springer Nature remains neutral with regard to jurisdictional claims in published maps and institutional affiliations. 